\title{
THE COMPLEXITY PARADIGM: TOWARDS A MODEL FOR THE ANALYSIS OF SOCIAL SYSTEMS AND PROBLEMS
}

\author{
UDC 316.344.233
}

\section{Artur Parreira ${ }^{1}$, Ana Lorga da Silva ${ }^{2}$}

\author{
${ }^{1}$ GESC - Santa Úrsula University, Rio De Janeiro, Brazil \\ ${ }^{2}$ Lusófona University, Lisbon, Portugal
}

\author{
ORCID iD: Artur Parreira https://orcid.org/0000-0002-5707-8787 \\ Ana Lorga da Silva (i) https://orcid.org/0000-0001-7514-8278
}

\begin{abstract}
The article proposes the complexity paradigm as an innovative reasoning for analyzing problems in behavioral sciences. It begins to explain the contributions of the major authors of the complex reasoning paradigm: Gödel, Prigogine and Morin. They offer the basis to a model of analysis and assessment of complex systems and problems (ACSIP Model). The four postulates of the Model are explained, emphasizing the principal hypothesis of the Model - the level of cognitive operations is the most important factor of complexity of a system; then to understand it, the cognitive level of analysis must be at minimum equal to that of the system or the problem under analysis. In the second part the article, an illustrative application of the ACSIP Model is applied to the analysis of the SDG 9 from the UN 20/30 agenda, showing the analysis of a complex problem, guided by the complexity reasoning model. Following that, an empirical research is presented, to verify the hypothesis underlying the fourth postulate of the model. The results confirm the hypothesis: the use of information by a group is inversely proportional to the use of power (authority). These results allow us to conclude that the complex reasoning paradigm is a promising tool to obtain synergic results in the scientific analysis and resolution of concrete social problems and to face the complex challenges brought by artificial intelligence systems.
\end{abstract}

Key words: Morin's operators; Cognitive complexity; ACSIP Model; Socioeconomic inequalities; Results synergy

JEL Classification: I32, J18

Received July 02, 2021 / Revised November 29, 2021 / Accepted November 30, 2021

Corresponding author: Ana Lorga da Silva

Lusófona University, Avenida do Campo Grande, 376 - 1749-024 Lisbon, Portugal

|E-mail: ana.lorga@ulusofona.pt

(๑) 2021 by University of Niš, Serbia | Creative Commons Licence: CC BY-NC-ND 


\section{INTRODUCTION}

The article explores the complexity paradigm as an innovative reasoning for analyzing social systems and problems, taking into account that they are usually quite entangled and requiring an interdisciplinary approach. The article has as its main objective the formulation of an analysis model based on the complex reasoning paradigm and the explanation of its core postulates and its interdisciplinary and multi-level analysis of social problems. To accomplish this purpose, we begin to record the path of the complexity idea in Psychology and other behavioral sciences, before advancing to the work of the authors who are the pillars of the complexity paradigm in present scientific realm.

Psychology addressed the problem of human cognitive complexity, as early as 1955 : Bieri (1955) was concerned with cognitive complexity and its effect on predictive behavior; Kelly, also in 1955, investigated the cognitive complexity in the structuring of personality; Nidorf and Crockett (1965), Karlins et al. (1967) and Schröder (1971a) continued these studies, exploring the effect of cognitive complexity on creativity, conflict resolution and the structure of personality, while others oriented themselves towards the integration of complex thinking into the area of organizational behavior: Mitchell (1971), studied the effect of cognitive complexity on team productivity; Streufert and Streufert (1978) and Streufert and Swezey (1986) explored the impact of context complexity on organizational behavior.

These studies address problems from a variety of models, but they all have some common bases:

- our mind is made up of interrelated cognitive processes, responsible for the organization of our knowledge;

- these cognitive processes occur in a certain order, albeit flexible; but the concern with the method, a core issue in addressing the cognitive complexity (Neufeld and Stein, 1999), is an evident trait;

- they are not restricted to their neurological support substrate, although they depend on it and its organization: the mind is a processor of symbols and meanings, which are related to the objects of the context;

- the human relationship with the external world is, therefore, intentional and autonomous.

The integration of the complexity paradigm in Psychology was continued by the work of authors such as Hooijberg, Hunt and Dodge (1997), Lichtenstein and Plowman (2009), Schneider and Somers (2006) or Uhl-Bien and Marion (2007), on leadership complex models and complex systems organization. The contribution of Psychology to the understanding and application of the paradigm of complex thinking cannot be ignored (Streufert, 2006); and the willingness of these psychologists to adopt different explanatory models, recognizing that the notion of complexity needs multiple approaches, in order to be fully understood and explained, expanded to other social sciences - mainly Sociology and Economy. We cannot forget the contribution of scholars of economic organizations, such as Herbert Simon, with their works on the limited rationality of our decisions (Simon, 1987), as well as on the architecture of cognitive complexity (Simon, 1962); von Neumann for his studies on cybernetic systems; the work of Albin and Göttinger (1983) on the complexity in the economic area; chemical and biological scientists such as Prigogine and his colleague Nicolis (1989); and sociologists such as Edgar Morin $(1977 ; 1990 ; 2001 ; 2011)$ and Le Moigne (1999) in social sciences epistemology. All these authors pave the ground which nourishes the complex reasoning paradigm, and mainly those who are the pillars of 
Model proposed in this article: Gödel, Prigogine and Morin. On the basis of these authors' ideas about the factors of systems complexity and the tools of complex reasoning, a model is formulated (ACSIP- Analysis of Complex Systems and Problems), with an interdisciplinary and multi-level view of social problems. Its aim is to understand the factors of systems complexity and their dilemmatic relationship, and to allow us to manage them at the cognitive level require by their complexity, in order to avoid any perverse effects, frequently observed, when interventions are not guided by the appropriate level of knowledge.

\section{ON THE SHOULDERS OF GIANTS: THE THREE PILlaRs OF A COMPLEX REASONING MODEL}

As it was stated by Bernardo de Chatres ${ }^{2}$, if our eyes can reach very distant horizons, this is due to the fact that we are seated on the shoulders of giants, those thinkers who opened our way to the knowledge we enjoy today: the three referred authors who are at the source of the complex reasoning paradigm and who established its pillars and mainstays.

\subsection{Gödel's foundational work}

The complexity paradigm, whose first foundation can be found in the work of Kurt Gödel (1931) on the incompleteness of the demonstrability of propositions recognized as true within a logical system, received theoretical contributions over time, from several authors. His work on the demonstration of the undecidable propositions and the formulation of the incompleteness theorems had a discreet repercussion; but it was the first stone of the new style of thinking that would come to be affirmed throughout the XX century, in several scientific domains. Beyond its repercussion on logic and mathematics, the idea of complexity impacted also on cognitive and social psychology and its interventions on organizational behavior: decision theory and cybernetic systems (Simon, 1962); research work on biological systems (Prigogineand Stengers,1997); studies on the complexity of economic processes (Albin e Göttinger, 1983); the work of sociologists like Le Moigne (1999), and psychologists, mainly from the area of Cognitive Psychology (Bieri, 1955) and Kelly (1955) and organizational behavior (Mitchell, 1971; Streufert and Streufert, 1978). In a tribute article on the centenary of Gödel's birth, Alkaine, says that Gödel's work shows the limits of reason, and therefore they should "be taken into account in modern areas of the exact sciences, since these works "greatly affected the way we think today" (Alkaine, 2006, p. 526). Gödel showed that the appearance of paradoxes in mathematics is inevitable; and to keep the system consistent with itself they must be accepted as undecidables: "propositions that cannot be decided as false or true within the system itself, but only from an external conceptual field. This is the price to pay for the consistency of the system" (Kubrusly, 2006, p.8). As Gödel argued at the Königsberg Congress on Epistemology of the Exact Sciences,

(1) If a formal system containing arithmetic is consistent, then it contains true arithmetic propositions which, however, are undecidable;

(2) There is no computable procedure to prove the consistency of the theory within itself (Lannes, 2014, p.4).

\footnotetext{
${ }^{2}$ It seems to have been Bernard of Chartres the father of the sentence which Newton (quoted in Hawking, 2003) made famous in a letter to Hooke "If I have seen further, it is by standing on the shoulders of giants".
} 
The truth or falsity of an undecidable, will always have to be based on a more comprehensive and less restrictive logic than that adopted for the mathematical system in question (Kubrusly, 2006). The impact of these two theorems turned out to be a liberating influence, when they triggered a new style of thought in epistemology (Fleck, 1979, quoted in Lannes, 2014); and this impact led precisely to a change in attitude towards the realm of science today, the arguments with which we intend to affirm it, their limitations and even the weaknesses of their roots.

Gödel's work showed that the logical foundation of an interpretative system of reality has to be sought in a conceptual system in a broader rationality. This requirement places Gödel as a primary source of the complex thinking paradigm, as it becomes visible in the letter from von Neumann to Gödel (quoted in Ferreira, 2006, p. 1):

I must testify all my admiration (...): you solved this enormous problem with masterly simplicity (...) to show that the consistency of mathematics is not demonstrable (...) Reading your study was really an aesthetic experience at the highest level.

This article aims to highlight the impact of this new style of thinking and transpose the practices which it recommends into the domain of the social sciences (Lannes, 2014). To do it, it explores the contribution of thinkers who are the pillars of the complexity paradigm and led to the change in attitude that is the heart of scientific thinking today.

Prigogine is responsible for some fundamental ideas that helped to broaden the horizons of scientific thought towards the incorporation of the idea of complexity, by his proposal of three main ideas:

- the end of certainties in science;

- the idea of bifurcation, which opens possible alternatives of structuring, based on the condition of unstable structures (dissipative structures), leading to more or less extensive changes;

- the irreversibility of time linked to the former concept, which enriched the meaning of the change processes with the idea of history.

\subsection{Prigogine's contribution}

Prigogine is responsible for some fundamental ideas that helped to broaden the horizons of scientific thought towards the incorporation of the idea of complexity, by his proposal of three main ideas:

- the end of certainties in science;

- the condition of unstable structures (dissipative structures) as a source of more or less extensive changes;

- the idea of bifurcation, which opens possible alternatives of structuring things, linked to the concept of time irreversibility, which enriched the meaning of the change processes with the idea of history.

\subsubsection{The end of certainties}

The end of certainties does not mean for Prigogine the empire of ignorance; what he underlines is that this new vision leads us to leave aside "the tranquil certainties of traditional dynamics" (Massoni, 2008, p. 2308-7). In place of them, to broaden their scope, Prigogine proposes that science incorporates indeterminism, which acquires a precise meaning: it is not the absence of predictability, but the knowledge of the limits of 
predictability (Prigogine, 1997): it expresses not what is right, but what is possible; and this possible is the new meaning of the laws of nature (Massoni,2008). Consequently, determinism breaks down, because everything is in motion in this universe of complex systems, with multiple possibilities open to the system (Prigogine, 2009). That is why the probability is directly linked to uncertainty or, if the term is preferred, to indeterminism.

On the other hand, the questions addressed in science are not eternal, they are linked to a determined historical time (Carvalho, 2014), they result from the questioning of previous knowledge and the growing disillusion caused by the answers it offers (Bachelard, 1940). This is the end of the neutral and seemingly timeless certainties, not the end of knowing which is complex. It only breaks the symmetry of temporal reversibility and integrates entropy as one of the indicators of the irreversibility of time. The awareness that the field of current science is not that of the tranquil certainties of classical determinism gets stronger: the new state of matter (far from equilibrium, which cannot be described by linear equations) forces us to see under another light the world around us, the phenomena of life, of time, of the multiplicity of structures. Scientific reasoning leaves the field of bounded certainty of linearity (Simon, 1962; 1987) and enters the territory of the multilinear possibilities to be explained, in line with Gödel's undecidable.

\subsubsection{The idea of dissipative structures and bifurcations}

Prigogine considered bifurcation the most important characteristic of complex systems, because "bifurcation is the critical point through which a new state becomes possible in nature" (Prigogine \& Stengers, 1997, p. 122). Bifurcations arise from two moments: disordered and turbulent movements due to forces that cause a state of imbalance in the system and push it to the edge of chaos; creation of dissipative structures of the energy which causes the state of imbalance. The dissipative structures allow order to emerge from chaos, from entropic movements, through the entrance of the system in one of the possible bifurcations open to the future ${ }^{3}$. "Each complex being is formed by a plurality of entangled times. In this way, history, as a process - of a living being or of a society - can never be reduced to the monotonous simplicity of a single time" (Prigogine \& Stengers, 1997, p. 211). In the succession of bifurcations, deterministic zones alternate between bifurcations and points of probabilistic behavior, the bifurcation points; in these bifurcations there are generally many possibilities open to the system. The appearance of the new structures is rooted in the energydissipating structures. This emergency implies time in a defined direction, which led Prigogine (1980) to assert that the logic of irreversible processes of systems far from equilibrium is not a logic of equilibrium, but a narrative logic, that is the activity of dissipative structures is defined as history and not just as a balance of energies. The result is a breakdown of determinism, even on the macroscopic scale (Prigogine \& Stengers, 1984).

The multiple possibilities open to the system cannot be reduced to a single scheme (Prigogine \& Stengers, 2009). The system can never be explained based on the simplicity of a single time path: it became complex, as it is constituted by a plurality of times in which past, present and future are interwoven. Any state the system is not something that can be deduced, as others were also possible. The explanation must be historical or genetic: to describe the path that constitutes the system's past, enumerate the bifurcations

${ }^{3}$ The challenge put by the COVID-19 pandemic is an example of an event at the edge of chaos, which forced the emergence of cooperative behavior even between political adversaries, more, between nations "geopolitical competitors". It may contribute to the emergence of a new world order. 
crossed and the fluctuations that decided the real history, among all possible ones (Prigogine \& Stengers, 1997).

Bifurcations introduce time as a fundamental variable: time no longer can be ignored, even in physico-chemical ones, where entropy is the indicator of an irreversible temporal movement. Eddington (1928) called it the arrow of time, because it indicates the degradation of the energy and the matter that constitute them. In living systems, which in addition to energy and matter exchange information with the environment, the emergence of new states (negentropy, as Morin designed it) is another indicator of the arrow of time $^{4}$. The arrow of time is the way we experience it, a subjective perception of what we ourselves are: the irreversibility of time is a function of movement in a finite system, subject to entropy processes, whose logic is that of narrative, not that of symmetrical balance. To know a complex system requires to know its past and calculate its future, based on a careful view of its past and present (Prigogine, 2008). The system is a totality of time ${ }^{5}$.

The multiple choices in the bifurcations define the degrees of freedom and intrinsic creativity of complex systems and force us to incorporate uncertainty as a component of knowledge, no longer as a negative posture, but as a way of seeing reality. A way more attentive to its multiple plans, more open and questioning, in which the certainty of what is known contains the awareness of its limitation, of its uncertainty, typical of all finite systems (Tarsky, 1933, quoted in Sher, 1999, p.150).

By scientifically contributing to the end of limited and limiting certainties, Prigogine continued Gödel's reflection on the inherent limitation of logical systems and the need to move up to higher conceptual systems, as a condition for understanding complex realities. Studying the emergence of order from states close to chaos, due to the dissipative energy structures and the opening of bifurcations, Prigogine took a decisive step to explain the changes which lead to the emergence of new structures and new meanings, an essential component of the dynamic complexity of the systems. Finally, with the idea that time is an irreversible path for living systems and that these can only be understood as complex history, Prigogine introduces another essential factor for complexity, in line with the dialogic and recursive principles, proposed by Morin to understand the circular processes that build the total complexity of the systems.

\subsection{Morin's fundamental contribution}

Edgar Morin is the most notorious author associated with the complex reasoning paradigm (Morin, 1990). According to him, all human activity obeys a tetralogy of relationships: order, disorder, interaction, (re) organization (Morin, 2011). Order and

\footnotetext{
${ }^{4}$ In physico-chemical systems, subject to the second law of thermodynamics, entropy is the indicator of the arrow of time (Eddington, 1928), because it marks the degradation of their energy and matter; in living systems, which exchange not only energy and matter with the environment, but also information, bifurcations and the emergence of new states (negentropy) are the second indicator of the arrow of time. The idea of the irreversibility of time may seem to contradict the position of Bradford Skow (2015), who defends the idea that all times are coexistent in the universal fabric of time: this is one of the constituents of the universe, and past, present and future would coexist in that fabric. But there is no contradiction: the arrow of time is the way we experience it, a relative perception, subjective to what we ourselves are. We can say, with Prigogine, that the irreversibility of time is a function of the movement in a finite system.

${ }^{5}$ Quoting Heidegger (1977), if the Dasein, the living human system, is a being to death, only in the end of his irreversible time, his own history, he can resolve the anguish of his existence, having reached his completeness and no more changeable identity (his totality as Dasein is now fixed).
} 
disorder must be understood as a pair in dialogical relationship, which produces new configurations, based on the interaction of the parties and their reorganization. In this process, cause and effect interact in a reciprocal movement, which is opposed to the simplicity of linear causality: time allows the feedback of the effects on their causes, forming a multidirectional complex causal circle. The complexity of a system results, therefore, from the multiplicity of its conditions and the variety of its movements (interaction and reorganization). The internal diversity of a system, the variety of its component parts, can be considered the first criterion for assessing complexity (static complexity); the variety of the internal movements adds to the diversity of the parts in the construction of complexity, as stated by Kochugovindan and Vriend (1998, p.56): "complex systems are based on a large number of agents, who interact with each other in various ways and modify their actions as a result of the events in the interaction process" (dynamic complexity).

To understand the complexity of the real, Morin proposes a method, which he himself rooted in three theories (Morin, 2011): the systems theory, and the idea that the whole is superior to its parts, since it exhibits emerged qualities; information theory, which places us in an universe where order and disorder coexist, where information has the role of creating new realities; cybernetics, which highlights the feedback processes: one (negative feedback), responsible for the stability of the system; the other (positive feedback), responsible for their change. From these roots, Morin elaborated the methodological principles of complex thinking, which constitute the framework of what he called the paradigm of complexity and proposes as an instrument for understanding the real. In his words,

disorder, translates into uncertainty (...) it brings chance, inevitable ingredient of everything that appears to us as disorder (...) every order process occurs due to a greater disorder - related to the second principle of thermodynamics (...) agitation, the encounter at random are necessary for the organization of the universe and that it is disintegrating that the world is organized - this is a typically complex idea because it unites the two notions, order and disorder. A strictly deterministic universe would be just order, it would be a universe without innovation, without creation (Morin, 2001, p.87).

The logical requirement for this way of reasoning must be greater than that of any simplifying thinking:

it is evident that a reality that is organized in a complex way requires, for your understanding, a complex thought, that ... must go beyond the closed entities, isolated objects, clear and distinct ideas, but also not to be confined in the confusion, in the vaporous, in the ambiguity, in the contradiction: it must be a game / work with / against uncertainty, imprecision, the contradiction (Morin, 2001, p. 87)

Morin (2011, p. 141) uses this logic in the tetralog, to explain the recursive circuit: complementary (societies, associations, mutualisms), competitive (competitions and rivalries) and antagonist (parasitism, depredation) relationships:

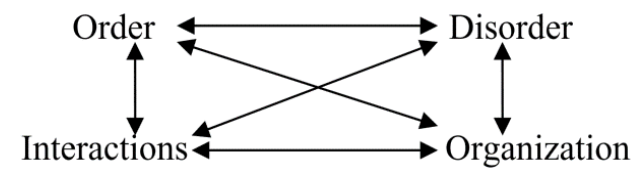

Fig. 1 The tetralog Source: Morin (2011, p141) 
The idea of complexity does not intend to replace concepts like clarity, certainty, determination and coherence by those of ambiguity, uncertainty and contradiction: it is based on the interaction and mutual work between such principles (Morin, 2001, p.88). It requires a strategic vision (not only tactical or operative) which Morin defined as the art of "using the information that emerges during the action, integrating it, formulating action plans and being able to gather as many certainties as possible, to face the uncertain". (Morin, 2001, p.90).

To put the tetralogic ring into practice, Morin proposes three conceptual operators: dialogic, recursive, holographic.

\subsubsection{The dialogic operator}

The dialogic operator (which Morin views as superior to the concept of dialectics) consists in identifying the different parts of the system as accurately as possible, to link what seems separate or even contradictory. The systematic use of the dialogic operator is fundamental to think the real, to apprehend it in its unity and multiplicity, not trying to explain it by its particular elements, which are reducing. This will help us to arrive at a "true, open rationality dialoguing with a reality that resists it, a rationality aware of its insufficiencies" (Morin, 2011, p.23). To do so it is crucial to understand the diverse and elaborate the concepts that allow to build the unitas multiplex: the unity of the whole which does not suppress, but on the contrary takes advantage of diversity.

\subsubsection{The recursive operator}

The recursive operator is related to negative and positive feedback processes proposed by Wiener (1961). To Morin, recursive causality is not limited to regulating processes or expanding deviations; it is ontological, it is an instrument for constructing the complex system itself:

At a higher level, recursion is translated by consciousness, the last emergence of complexity, specific of the human spirit (...) consciousness is reflexive, implies an unceasing return to the thoughts that produce it, to transform them ... providing the faculties of doubt, of self-examination...consolidating in ourselves the uniduality of the observed subject and the subject who observes (Morin, 2011, p.143).

It is not a linear relation - cause $\rightarrow$ effect - but it is about understanding the interactions that unfold the system and make it evolve, in the whole and in its parts, as it builds itself along the arrow of time (an arrow in spiral, where setbacks are present overvaluations of the weight of past causes).

\subsubsection{The holographic operator}

According to Morin himself, the idea of this operator came from systems theory and directly from the contact with Atlan and his ideas about self-organizing chance and the autopoiesis of complex living systems (Atlan, 1994). The self-organization of the system as a whole results from the emergence of integrating components and qualities, through the recursive process. So, holographic reasoning requires an effective knowledge of these components and the perception of their contribution to a different whole, which receives meaning from its parts, but which also gives to each of them a sense of their own. The whole is not a pot pourri of confused ideas, but the clarity of the particular in the whole 
and the clarity of the whole in the particular. It is the effort to understand the complexity of a real that can only be well understood in this dialogical junction of opposites.

Thinking the real and a knowledge based on these operators is at the heart of Morin's ideas about complexity. His reflection includes the essential epistemological acquisitions of the authors who have explored this paradigm:

- the lesson of Gödel's paradox: to explain a complex phenomenon one has to look for knowledge outside it (in the context, in higher-level models); otherwise, the system will always contain undecidable propositions, which we believe to be substantiated, but which cannot be demonstrated within the system;

- the concept of dissipative structures, from Prigogine, that allow to understand the emergence of a new order with a new meaning, expressing the dynamic complexity of the system;

- the belief that humans must be operators of complexity, capable of overcoming a mere intra-disciplinary reasoning and building a multidimensional, interdisciplinary science;

- the idea that information is the tool for reflexivity, self-reference, creativity, because it is the articulating axis of the constructed real (subject-object): it "allows us to move beyond the paradigm of classical science and logic, without rejecting them, but integrating them in the paradigm of complexity "(Morin, 2011, p. 151). This opens a door to other levels of reality (Nicolescu, 1999) and new insights, in the spiral path of knowledge construction.

Morin's reasoning is completed by Kaufmann (1993; 1995) and Gell-Mann (1994), who advance in the elaboration of an operational model of complex reasoning.

Kaufmann argues that complexity is based on four variables: N, number of system components; $\mathrm{K}$, the level of components interactions; $\mathrm{P}$, the common elements between the components which ensure the emergence of the totality; $\mathrm{C}$, the interactions of the system and its components with other entities in the context. Gell-Mann emphasizes the role of information in defining the level of complexity, pointing out that the complexity of a system is a function of the difficulty in describing it, verbally or mathematically, making explicit a fundamental aspect of the concept of complexity. With this Gell-Mann explains a fundamental aspect of the concept of complexity, already touched on by Morin and anchored in Gödel's incompleteness theorem.

\section{A COMPLEX MOdEL FOR SYSTEM AND PROBLEM ANALYSIS}

Starting from the ideas proposed, four postulates are delineated, which define a complex reasoning model, for the analysis and evaluation of systems and problems in human and social sciences. The first postulate of the Model defines the static (structural) complexity of a system and is based on:

- Morin's idea that the whole is more than its parts (it has properties that emerge and are not in them), but it is simultaneously less than its parts (constituting itself as such, it inhibits potentialities inherent in the parts that constitute it);

- Kaufmann's (1995) idea that the complexity of the system is determined by the number of parts that make it up.

First Postulate - The greater the number of different parts of a system, from which its global identity emerges, the greater is its complexity (static complexity). 
The Second postulate combines Prigogine's ideas - the emergence of new configurations in systems far from equilibrium (due to the dissipative structures of energy and the bifurcations they open in time) - and Morin's ideas about recursive processes and the tetralogic ring (the interactions that create order/disorder, organization/disorganization). But, in addition to these movements of internal dynamics, there is the external dynamics of interactions with the context, which integrates physical, economic, social, cultural, political factors. These movements as a whole define the dynamic complexity of the system.

Second Postulate -The internal and external movements of the system define its lived history, subject to the process of irreversibility of time, whether they are entropic or negentropic movements. The greater the variety of these movements, the greater, ceteris paribus, the complexity of the system (dynamic complexity).

There is yet another criterion to define complexity: the level and mode of integration of diversity in a system with its own identity. The system is not the mere sum of its parts, it is built as a unitary whole, continually emerging from the interaction of these parts, integrating the nature of each one in a new nature, its own as a system. That is why Morin called it unitas multiplex, a unit of multiplicity:

The unit of the system is not the unit of unum, it is simultaneously one and not one. There is a loophole and shadow in the logic of identity. We have already seen that there is not only diversity in the one, but also relativity of the one, otherness in the one, uncertainties, ambiguities, dualities, splits, antagonisms (Morin, 1977, p. 140).

The processes of articulation and integration of these parts, leading to distinctive patterns of behavior, are, therefore, nuclear. The integration of diversity in the unit can be achieved through two processes: the use of energy (power, in human systems); and information, which articulates diversity, through the discovery and use of adjustment processes that take advantage of it. Morin extensively advocates the role of information in building complexity. In his matrix idea, obtaining the unity of a system through the use of power leads to a more or less extensive reduction in diversity, because the unification by the use of power forces us to homogenize what is integrated; building unity and simultaneously maintaining diversity is only feasible by learning new and more comprehensive ways and by exchanging information, until a suitable format is found. This new format, therefore, necessarily integrates more information than the previous ones. This is the idea that supports the third postulate of the Model.

Third Postulate - The more the emergence of the identity of a system from its components is carried out through information and not power processes, the greater will be its internal variety, the higher the informational level of interactions and, consequently, the complexity of the system.

Thus, the substantive complexity of a system can be assessed on the basis of its position in the criteria established by the postulates. Similarly, an explanatory model based on these postulates is an instrument for the operational use of complex reasoning, the main challenge of this article: to build a model of cognitive complexity suitable for the analysis of complex systems and problems that we face in the social sciences area. The fourth postulate takes up the idea of Gödel's undecidables and expresses the cognitive conditions of the complex reasoning paradigm, highlighted by the Gell-Mann criterion: the complexity of a system is all the greater the more difficult is its verbal or mathematical description. 
Fourth Postulate - To understand a system or to solve a problem with a certain level of information complexity, it is required a cognitive complexity, at a level equal or above the informational complexity of the concerned system or problem.

The figures 2 and 3 show the interactions between the model's variables and present the basic formulas that express them.

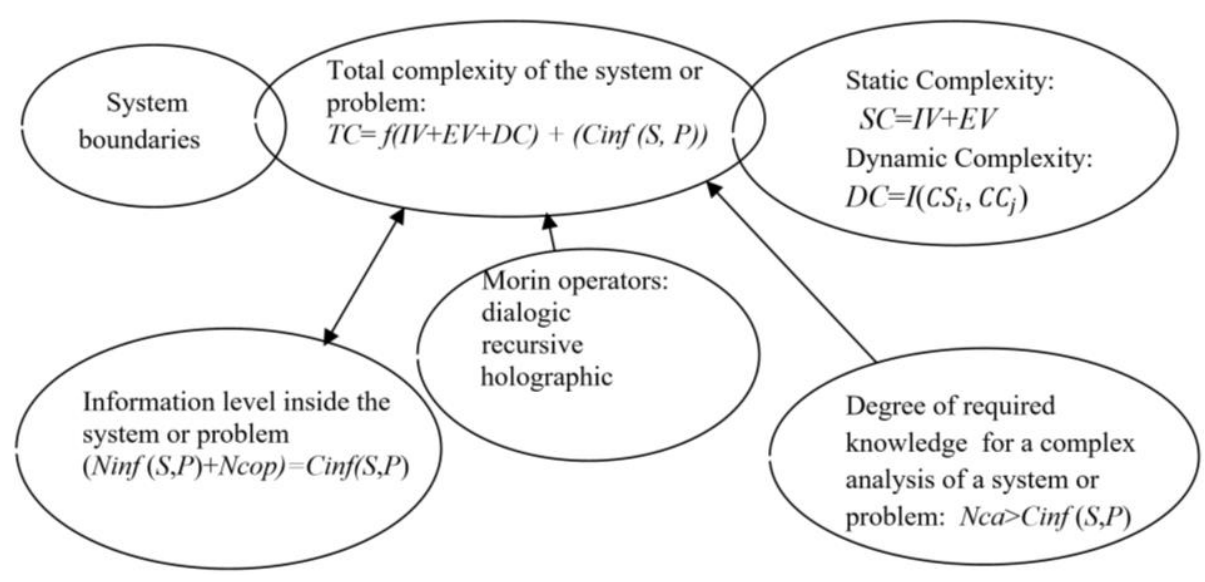

Fig. 2 The ACSIP Model - complex analysis of systems and problems Source: authors

Where:

$I V=\sum_{i=1}^{n} C S_{i}-$ internal variety of the system or problem

$C S_{i}-i=1, \ldots, n$ the systemcomponents or the dimensions of the problem

$V E$ - external variety of a system $V E=\sum_{j=!}^{m} C C_{j}$

$C C_{j}-j=1, \ldots, m-$ context components interacting with the system

$C D$ - system's dynamic complexity (which varies over time)

$C D=I\left(C S_{i}, C C_{j}\right)$, so as $I-$ competitive interactions and resolutive interactions

$S$-system

$P$ - problem

$\operatorname{Cinf}(S, P)$ - information complexity of the system or problem

$\operatorname{Ninf}(S, P)$ - information level inside the system or the problem, which includes gi $(S, P)$

$g i(S, P)$ - interdisciplinarity degree inside the system or the problem

$\mathrm{Nca}$ - level of knowledge at what analysis is conducted 


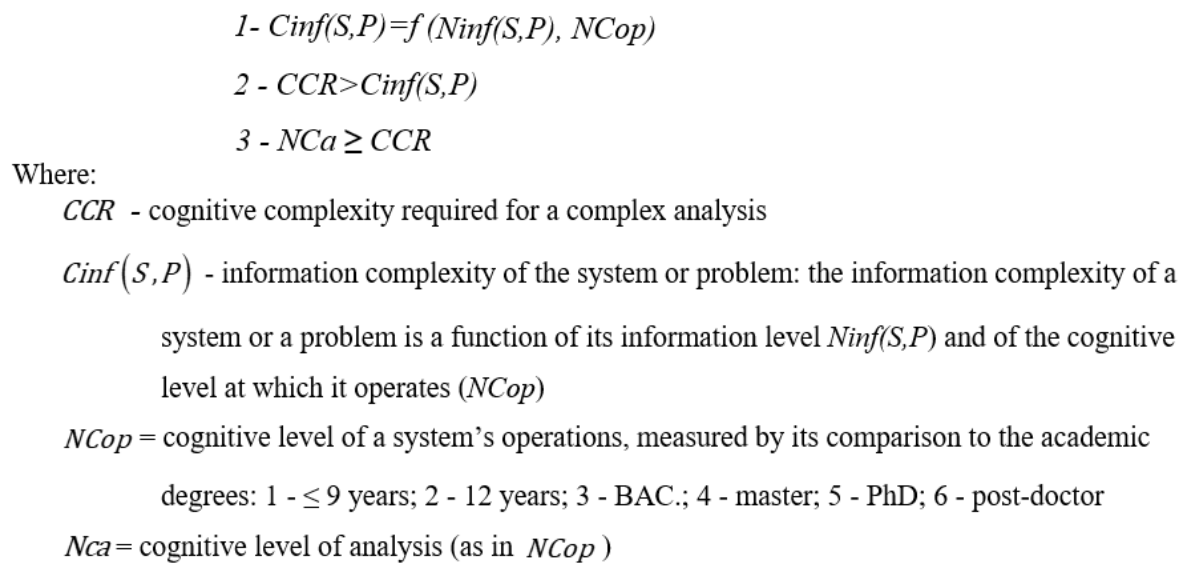

Fig. 3 Formulas for the required complexity of analysis Source: authors

The first formula expresses the complexity of a system or a problem as defined in the first three postulates of the ACSIP Model: it is derived from the combination of the number of different components of the system or the problem (VI); the internal movements of these components; external movements in the system's relationship with its context; and the informational level inherent in the system and its operations $(\operatorname{Ninf}(S, P))$. The second and third formulas are directly related to the fourth postulate of the Model: the second defines that the required cognitive complexity has to be greater than that of the system or the problem $(C C R>\operatorname{Cinf}(S, P))$ to be capable to understand and explain it; the third indicates the requirements to be met $(N c a \geq C C R)$, so that the analysis of a complex system or problem can resolve them.

\section{ENTERING INTO THE PRACTICE OF COMPLEX REASONING}

We enter now into the empirical part of this study: the impact of several power conditions on the operationalization of information by problem-solving groups is evaluated, to test a hypothesis (H1) related to the postulates three and four of the Model: the use of useful information for the analysis and resolution of problems is all the greater the less the power used in the interactions between the leader and the group and among members themselves.

Secondly, the operationalization of the ACSIP Model is shown, using an example of the analysis and decision of a complex problem, posed by the SDG 9 of the UN 20/30 agenda, 2017.

At the individual level, cognitive complexity requires to develop an interdisciplinary attitude, with the perception of the divergent and the ability to ask and dialogue with divergent knowledge views. To achieve this attitude, sufficient emotional self-regulation is required (Bar-on, Maree \& Elias, 2007), based on the well-known criteria of emotional intelligence (Goleman, 1996):

At the individual level, cognitive complexity requires mainly to develop an interdisciplinary attitude, with the perception of the divergent and the ability to ask and 
dialogue with divergent knowledge views. To achieve this attitude, sufficient emotional self-regulation is required (Bar-on, Maree \& Elias, 2007), based on the well-known criteria of emotional intelligence (Goleman, 1996):

- the self-regulation of emotions allows to increase the quantity and diversity of descriptors used in explaining the real, and better encompass the internal and external variety of the analyzed system or problem (Kaufmann, 1995);

- the increase in the variety of descriptors raises the level of interpretations, as it increases the ability to integrate divergent or contradictory information (Morin's dialogic operator; Gell-Mann's proposal);

- the level of precision in the use of descriptors makes them operationally more effective, explaining more completely the global identity of what is analyzed, and its context (Morin, 2001).

But today, scientific and technical interdisciplinary analysis cannot be individually guaranteed: it requires the support of a team that accepts that diversity and builds interdisciplinary models of high enough level to integrate diverging views, without distorting them. To ensure an open discussion and the exchange of useful information, the analysis team must be conducted by a participative leadership centered on the search for information ${ }^{6}$ (Parreira, 2010), excluding or greatly reducing the usual forms of power.

However, the complexity required to the human subject goes beyond the purely cognitive domain. Interventions in nature and society, without adequate knowledge of its impact on reality, can lead to dangerous, often not realized, changes. Actually, intervening on the real implies using technology and technology is mainly power, requiring an accurate knowledge of its potential effects. It is a challenge to the human operator: all these studies and the proposed Model point to the advantage of increasing the complexity level of reasoning in people, teams and organizations; but, as Streufert and Strufert (1978) state, the training of cognitive complexity, although difficult, is possible.

\subsection{An empirical test of a hypothesis related to the third and fourth postulates}

The use of the highest level of information available is essential for an analysis covering the complexity of the problems to be resolved. The hypothesis (H1) to be tested is derived from the stated postulates.

H1: the use of useful information for the analysis and resolution of problems is all the greater the less the power used in the interactions between the leader and the group and among members themselves.

To test H1, a questionnaire survey was carried out, with a sample of university teachers and students, with the objective of measuring the impact that the use of power by the leader and members of a group could have on the utilization of information, when analysing and finding solutions for problems faced by the group.

\subsection{The instrument}

The instrument used in the research was a questionnaire in the format of a semantic differential; this format was chosen to make it easier for respondents to simultaneously

\footnotetext{
${ }^{6}$ Participatory leadership is used here in the definition of the Multiplex Model (Parreira, 2010): leader-group interactions are extensively of a resolutive and non-competitive type; using restricted power, varying only with the task and preparation of the group, always privileging information as asked by Morin.
} 
consider the two types of possible impact (positive and negative) associated to the power behavior pattern. Responses are given on an interval scale based on adverbs of quantity (each adverbial position has a numerical value established in studies carried out since 2003).

The questionnaire has construct validity, since the items describe situations presented in the studies of the classic authors on leadership and power (Day, 2014), and are part of the experience of people in different work contexts. In addition, the questionnaire was subjected to a pre-test in three groups of people of different profession and education (over 12 years of schooling), and their observations led to modify some aspects of the wording describing the stimulus situations.

Six situations are presented, and respondents evaluate the possible impact of the power described in each one on the operationalization of information; the evaluations are made in the above referred scale. It is written in Portuguese and translated into English, in this paper.

\subsubsection{An example of the initial instructions and the two extreme situations}

Probably you have already experienced situations where the leader and the group members used to a greater or lesser extent attitudes of power and authority, to make the group accept the solutions they proposed; in other situations, this pressure was less or almost not used. Please pay attention to the situations presented below and try to assess to what extent attitudes of power in the group have a negative or a positive impact on the use of useful information to resolve the problems.

If you think that the behavior described in the situation has a negative impact, please mark $X$ in the adverb that best corresponds to your idea, in the left branch of the scale; if you consider that the described behavior has a positive impact, mark $X$ in the adverb that best corresponds to your idea, in the right branch of the scale. If you have no idea about the possible impact of the described behavior, mark $X$ in the box "I can't decide". All answers are correct, as long as they express what you actually think.

Table 1 The two extreme situations presented in the questionnaire

1. The leader and group members used extremely competitive attitudes and enforced their ideas, when analysing problems and discussing solutions to them. It was extremely difficult to convince them to analyse any idea divergent from their own.

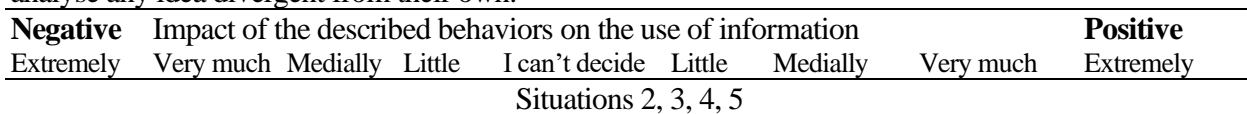

6. The leader and group members almost did not use competitive attitudes nor imposed their ideas, when analysing problems and discussing solutions to them. Their attitudes were very open and everyone always accepted to analyse and discuss any solution, even if it was divergent from his own.

\begin{tabular}{llllll}
\hline Negative & Impact of the described behaviors on the use of information & & Positive \\
Extremely & Very much Medially Little & I can't decide Little & Medially & Very much & Extremely \\
\hline
\end{tabular}

The used scale, expressed in quantity adverbs may be an example of the fruitful synergy between qualitative and quantitative methods: it is a mix of a qualitative expression (adverb), used currently to evaluate objects and situations, and a quantitative measure (numerical interval scale), based on the numerical value attributed to the adverbs and adverbial expressions, in studies carried out since 2003 (Parreira \& Lorga da Silva, 2016). 
The authors believe that this enhances the validity of the scales, namely because they are not a mere ordinal but an interval scale (between nothing at all $(=0.54)$ and extremely $(9.25)$, the values obtained in the referred studies The qualitative-quantitative mix is reinforced by the description of situations as behavioral complex situations; so, the respondents must understand the described behavior and evaluate its impact as resulting from the situation, perceived as a unit. This highlights, once more, the synergy between qualitative and quantitative methods, showing that every number tells a qualitative story Bancaleiro (2006).

The questionnaire was subjected to Cronbach's alpha procedure, to evaluate its reliability. As seen in Table 2, the instrument has good reliability (0.86), so it can support statistical analysis and interpretations related to the measurements obtained, who had no difficulty in understanding its questions. The questionnaire was also subjected to Cronbach's alpha procedure, to evaluate its reliability. As seen in Table 2, the instrument has good reliability (0.86), so it can support statistical analysis and interpretations related to the measurements obtained.

Table 2 Cronbach's Alpha from P-I questionnaire

\begin{tabular}{lcc}
\hline & $\mathrm{N}$ & Cronbach's Alpha \\
\hline Cases & 225 & 0.861 \\
\hline \multicolumn{3}{c}{ Source: authors }
\end{tabular}

\subsubsection{The sample}

The sample was composed of 225 university students and teachers and collected between September and November 2019.

Sample structure: 153 students, from the third year of Management, Economy, Sociology and Political Science courses; 72 teachers of the referred courses.

Male respondents: 149; female respondents: 76; no other gender signaled

\subsubsection{The results}

Table 3 shows that the variables - use of power and use of information - have a strong negative correlation. It is a first confirmation of the stated hypothesis..

Table 3 Correlation between the use of power and the use of information

\begin{tabular}{llcc}
\hline & & Power used & Managed information \\
\hline Power used & Pearson correlation & 1 & $-.857^{* *}$ \\
& Sig. (2-tailed) & & .000 \\
& $\mathrm{~N}$ & 225 & 225 \\
\hline Managed information & Pearson correlation & $-.857^{* *}$ & 1 \\
& Sig. (2-tailed) & .000 & 225 \\
& $\mathrm{~N}$ & 225 & \\
\hline & & ${ }^{* *}$ Correlation significant at 0,01 level (2-tailed) \\
& \multicolumn{2}{c}{ Source: authors }
\end{tabular}


Table 4 Impact of different levels of power on the use of information, by gender

\begin{tabular}{lccc}
\hline Power behavior used in situations & \multicolumn{2}{c}{ Information utilized (mean) } & Difference between means \\
\cline { 2 - 3 } & Women & Men & \\
\hline Situation 1 (extreme power used) & 1.4643 & 2.3889 & 0.9246 \\
Situation 2 (much power used) & 2.2957 & 2.7389 & 0.4432 \\
Situation 3 (a lot of power used) & 2.8414 & 3.3206 & 0.4792 \\
Situation 4 (medium power used) & 2.8414 & 3.3206 & 0.1356 \\
Situation 5 (Little power used) & 5.6033 & 5.7389 & 0.2075 \\
Situation 6 (Almost no power used) & 7.6986 & 7.4911 & 1.0676 \\
\hline
\end{tabular}

Source: authors

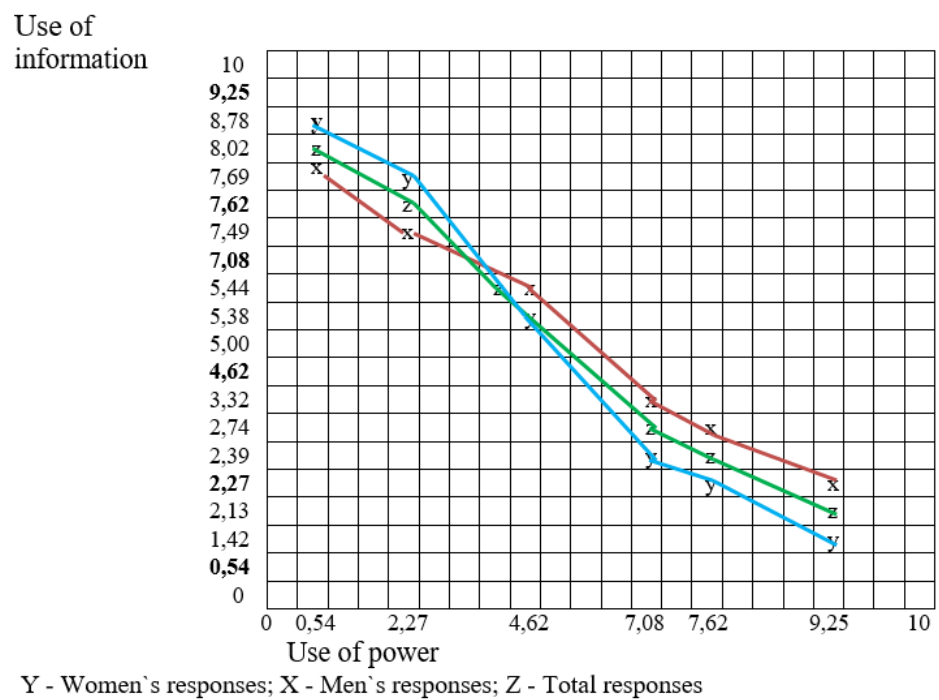

Fig. 4 Use of power and utilization of information in group data analysis and problem solving Source: authors

When the use of power is great (extremely; a lot) the inhibition of the use of information is stronger in them; conversely, when power is little or very little used, the positive effect on the use of information is more evident in women than in men. As power has an impact on people through emotions, which are the energetic basis of human motivators (Pestana, Parreira and Moutinho, 2020), this difference may have a psychological explanation, the natural stereotype that emotions are stringer in women; however, the differences are not statistically significant.

However, the results are interesting in two ways:

- they confirm H1, showing that people perceive the negative impact of power attitude and tactics on the effective use of information in problem analysis and solving;

- they offer guidelines for the practice of leadership in problem solving and creativity groups. If a leader wants to make good use of the group's knowledge (large or small), he must reduce the use of power practices: these lower the level of truth in interactions; decrease the number of initiatives to inform the leader and 
the group; distort the perception of the real; reduce the objectivity and relevance of the information provided. To do so, it is crucial to prepare the group to adopt predominant information-based practices; if it has a low level of knowledge and works essentially on an emotional basis, the leader must use more power to lead the group; but in that case, he must not forget that this behavior reduces group intelligence. As information is a more flexible and positive tool than power, the model advises to adopt a participative leadership, as much as the situations allow it (Parreira, Pestana and Oliveira, 2018).

If a leader wants to make good use of the group's knowledge (large or small), he must reduce the use of power practices to adopt predominant information-based practices; if it has a low level of knowledge and works essentially on an emotional basis, the leader must use more power to lead the group; but in that case, he must not forget that this behavior reduces group intelligence. As the information instrument is more flexible and positive than the power instrument, the model advises to adopt a participative leadership, as much as the situations allow it (Parreira, Pestana and Oliveira, 2018).

\subsubsection{An example of problem analysis, guided by the ACSIP Model}

We can now advance to the second part of this section and present an example of analysis and decision on a complex problem, guided by the ACSIP Model.

Problem: To reduce inequality within (and between) nations (SDG 9 of the UN 20/30 agenda, 2017)

This problem was chosen for its connection with other problems (poverty, education, health, as the UN text states itself) and the transformation of the world economic model, now discussed by scientific and academic groups involved with the so called "Pope Francisco's Economy", but also by political leaders, moved by the COVID-19 pandemic crisis and the climate threats.

The example is focused in the inequality within nations which is sufficient to highlight the modus operandi of the ACSIP Model, will follow an identical path in the analysis of other complex problems.

\section{First step:}

1. Define the physical boundaries of the system

Locate the problem in the system

Define with extent and precision the system and its physical boundaries.

Example: State of Brazil, Rio de Janeiro (RJ),

Questions: - Is the geographic and geological situation (oil exploration and related economic processes, for example) a negative or positive factor to the inequality phenomenon?

- How do the economic, sociocultural, political features of the State impact the observed inequality (including migrants from other States)?

- How are the relations with different entities of the context a positive factor to the inequality phenomenon?

2. Indicators for this analysis: traditional and current cultural practices; educational indicators; socioeconomic indicators; urban indicators; data on population movements and attitudes.

3. Assess how the system characteristics affect the complexity of the problem.

Result: The problem is located and the variables to analyse are identified. 
Second step - Determine the informational complexity of the problem

1. The informational complexity of the inequality problem $(\operatorname{Cinf}(S, P))$ includes its different dimensions, focused on the Model's interdisciplinary approach. Sociology, with a focus on social diversity and the drivers of inequality; Psychology, focused on the individual and patterns of interaction;

Economy, focusing on income and employment issues;

Medical sciences, focused on health-related issues;

Urbanism and Architecture, with a focus on housing conditions, the quality of surroundings and mobility;

Political Science, applied to the study of individual rights and citizenship conditions.

Third step - Determine and ensure the level of required knowledge

1. Ensure the appropriate level of knowledge: is it sufficiently complex (in each discipline involved) for a comprehensive analysis and an effective solution to the problem?

In SDG9, the complexity of the problem appears to be very high, in each discipline; therefore, the available level for the analysis and construction of solutions must be at the doctoral level, to fully understand the issues and to elaborate effective and encompassing solutions.

2. Ensure an analysis team with at least one doctorate in each discipline involved.

3. Check whether the work team shows effective open mind, listens to every argument, values information - even divergent, avoids rigid or authoritative positions in the problem discussion and analysis, demonstrating that team operates $N C a \geq \operatorname{Cinf}(S, P)$.

4. Ensure that the methodologies and technical instruments used are based on the criteria of the required interdisciplinarity and are adequate to the required cognitive level: interview; questionnaire; impersonal and participant observation methods; urban and architectural methods of analysis; methods and criteria of economic analysis; interpretation of data based on an interdisciplinary view.

Fourth step - Ensure that the methodologies and technical instruments used are based on the criteria of the required interdisciplinarity

1. Check the use of the dialogical operator in the analysis of all the variables: variables interact; how much synergy is seen in the results; what contradictions are visible; where interdependencies manifest themselves.

Example: interactions between inequality and: poverty, education, housing, exclusion, inequality; and between each one with the others.

2. Check the use of the recursive operator in the analysis of causal relationships and their effects in the set of identified variables.

To what extent can causal relationships be checked and controlled in the set of identified variables.

3. Verify the use of the holographic operator in the interpretation of the data and proposed solutions.

To what extent is it possible to have an integrated view of the problem? How do the components build the whole and how it maintains each component's identity? Example: establishing a general framework of indicators and drivers of inequality, combining effects of social, cultural and gender barriers; measuring socioeconomic competition intensity, poverty level, housing conditions and personal history.

Result - A unitas multiplex portrait of the problem is accomplished, as the Model recommends. 


\section{Fifth step - Establish a flexible and adaptive action plan}

The knowledge obtained is a solid basis for triggering factors to reduce inequality, assessing their impact multidimensionally, following the ACSIP Model requirements, namely the process of informed negotiation7, recommended in point 3 of the third step.

Result - That will most probably ensure the control over internal and external effects of the decisions made and lead to solutions free of perverse effects

\section{AN OPEN CONCLUSION}

As an open conclusion, we underline the goal of this article: to highlight the impact of the complex reasoning paradigm, and transfer it to the social and behavioral research practices, as Lannes (2014) recommends. The results enhance the importance of the work of the authors which were considered the basis of this way of thinking: Gödel's foundational work; Prigogine's explorations about the end of certainties, dissipative structures and bifurcations; Morin, with his epistemological scheme of complex qualitative and quantitative reasoning.

The flexibility of complex thinking allows us to adjust the model to a wide variety of problems, including complexity of real problems, where the data are certainly much more entangled than those shown in the chosen example, requiring undoubtedly more powerful tools, with a longer, heavier and more complicated process. But the level of complexity was sufficiently highlighted: a multi-level interdisciplinary analysis, to capture the complexity of the problem and ensure a more informed decision-making, at a higher conceptual level, therefore less likely to generate perverse effects.

Focused on these results, the authors are willing to continue this study, convinced that the complex reasoning paradigm is a promising tool to face the challenges resulting from the expansion of new technological systems into all fields of human life.

\section{REFERENCES}

Albin, P., \& Göttinger, H. (1983). Structure and Complexity. Economic and Social Systems. Mathematical Social Systems, 5, 253-68.

Atlan, H. (1994). Entre le Crystal et la Fumée: essai sur l'organisation du Vivant [Between the crystal and the smoke: an essy on the organization of living systems]. Paris: Éditions du Seuil.

Bachelard, G. (1940). La Philosophie du Non [The No Philosophy]. Paris: PUF

Bancaleiro, J. (2006). Scorecard de Capital Humano - Como medir o activo mais importante da sua empresa [Human Capital: how to measure the most importante asseto f your business]. Lisbon: Editora RH.

Bar-On, Reuven, Maree, J. G., \& Elias, M. J. (2005). Educating people to be emotionally intelligent. Portsmouth, NH: Heinemann Educational Publishers.

Bieri, J. (1955). Cognitive Complexity-Simplicity and Predictive Behavior. The Journal of Abnormal and Social Psychology, 51(2), 263-268. https://doi.org/10.1037/h0043308

Bruner, J., Goodnow, J., \& Austin, A. (1956). A study of thinking. New York: Wiley.

Brundtland, G. (1987). Our Common Future-Call for Action. Environmental Conservation, 14(4), 291-294. https://doi.org/10.1017/S0376892900016805

Carvalho, R. F. (2017). As contribuições do físico-químico Ilya Prigogine para uma nova compreensão da História [The contributions of the physicist-chemist Ilya Prigogine to a new understanding of history]. Brasília, 24-28, july. Proceedings of XXIX National Simposium on History - Against prejudice: History and Democracy.

D’Alkaine, C. V. (2006). Os trabalhos de Gödel e as denominadas ciências exatas. Em homenagem ao centenário do nascimento de Kurt Gödel [Gödel's works and the so- called exact sciences. In tribute to the centenary of

${ }^{7}$ The concept of informed negotiation is characteristic of complex reasoning: what effectively develops systems is information and not power; this can be useful or necessary, but always in accessory and limited condition. 
the birth of Kurt Gödel]. Revista Brasileira de Ensino de Física, 28,(4), 525-530. https://doi.org/10.1590/ S0102-47442006000400015

Davenport, Th., \& Prusak. L. (1998). Working Knowledge: How Organizations Manage What They Know. Harvard Business Press

Day, D. (Ed.) (2014). The Oxford Handbook of Leadership and Organizations. Oxford: Oxford University Press.

Eddington, A. S. (2014). The Nature of the Physical World. An Annotated Edition Cambridge Scholars Publishing.

Eysenck, M. W., \& Keane, M. T. (2007). Manual de psicologia cognitiva Handbook of Cognitive Psychology ( $5^{\mathrm{a}}$ ed.). Porto Alegre: Artes Médicas.

Ferreira, F. (2006). A matemática de Kurt Gödel [Kurt Gödel's Mathematics]. Boletim da Sociedade Portuguesa de Matemática, 55, 39-62.

Gödel, K. (1986). Über formal unentscheidbare Sätze der Principia Mathematica und verwandter Systeme, I. (1931) [On formally undecidable propositions of Principia Mathematica and related systems]. In Solomon Feferman, (ed.), Kurt Gödel Collected works, Vol. I. Oxford University Press: 144-195.

Goleman, D. (1996). Inteligência Emocional [Emotional Intelligence]. Lisbon: Círculo de Leitores,

Gell-Mann, M. (1994). The Quark and the Jaguar. Londres: Little Brown and Co.

Heidegger, M. (1977). Sein und Zeit [Being And Time]. Frankfurt am Main: Vittorio Klostermann.

Hooijberg, R., James, G. H., \& Dodge, G. E. (1997). Leadership Complexity and Development of the leaderplex Model. Journal of Management Leadership, 23(3), 375-408.

Karlins, M. (1967). Conceptual complexity and remote-associative proficiency as creativity variables in a complex problem-solving task. Journal of Personality and Social Psychology, 6(3), 264-278. http://dx.doi.org/10.1037/ h0024740

Kauffman, S. A. (1993). The origins of order: self-organization and selection in evolution. Oxford University Press, Oxford.

Kauffman, S. A. (1995). At home in the Universe: the search for the laws of self-organization and complexity. Oxford University Press, Oxford.

Kelly, G. A. (1955). The psychology of personal constructs, vol. 1. New York: Norton.

Kochugovindan, S., \& Vriend, N. J. (1998). Is the Study of Complex Adaptive Systems Going to Solve the Mystery of Adam Smith's "Invisible Hand”?. The Independent Review, v.III, n.1, 53-66.

Kubrusly, R. S. (2006). Uma viagem informal ao teorema de Gödel (ou o preço da matemática é o eterno erro matemático) [An informal trip to the gödel theorem (or the price of mathematics is the eternal mathematician error)]. im/ufrj

Lannes, W. (2014). Sobre as implicações do Teorema de Gödel na organização social de Matemáticos e Lógicos no Século XX [On the implications of Gödel's Theorem in the social organization of Mathematicians and Logicians in the 20th Century]. Proceedings of $14^{\circ}$ National Symposium on History of Science and Technology Belo Horizonte, Campus Pampulha, Federal University of Minas Gerais, Brazil, 08-11 de october.

Le Moigne. (1999). Inteligência da Complexidade [Intelligence of Complexity]. In: Pena-Vega, A., Almeida, E.P. (Orgs.). O pensar complexo: Edgar Morin e a crise da modernidade Complex thinking: Edgar Morin and the crisis of modernity Rio de Janeiro: Garamond.

Lichtenstein, B. B., \& Plowman, D. A. (2009). The leadership of emergence: A complex systems leadership theory of emergence at successive organizational levels. The Leadership Quarterly, 20(4), 617-630. https://doi.org/10.1016/j.leaqua.2009.04.006

Massoni, N. T. (2008). Ilya Prigogine: uma contribuição à filosofia da ciência [Ilya Prigogine: a contribution to the philosophy of science]. Revista Brasileira de Ensino de Física, 30(2), 2308-1-2308-8.

Mitchell, T. (1971). Cognitive Complexity and Group performance. The Journal of Social Psychology, 86(1), 35-43. https://doi.org/10.1080/00224545.1972.9918592

Morin, E. (1977). La Methode 1. La Nature de la Nature. [The Method 1. The Nature of the Nature]. Paris: Éditions du Seuil

Morin, E. (1990). Introduction à la pensée complexe [Introduction to Complex Thinking]. ESF, Paris

Morin, E. (2001). L'Humanité de l'humanité (t. 5), L'identité humaine [The Humanity of Humanity, 5: Human Identity]. Paris: Le Seuil.

Morin, E. (2011). Mes Philosophes [My Philosophers]. Paris: Éditions Germina.

Neufeld, C. B., \& Stein, L. M. (1999). As bases da Psicologia Cognitiva [The Bases of Cognitive Psychology]. Revista da Saúde, 3(2), URCAMP, jul./dez.

Nicolis, G., Prigogine, I. (1989). Exploring complexity: An introduction. NY: W. H. Freeman.

Nicolescu, B. (1999). O Manifesto da Transdisciplinaridade [Transdisciplinarity Manifest]. São Paulo: TRIOM.

Nidorf, L. J., \& Crockett, W. H. (1965). Cognitive Complexity and the Integration of Conflicting Information in Written impressions. The Journal of Social Psychology, 66(1), 165-169, https://doi.org/10.1080/00224545.1965. 9919632

Parreira, M. (2010). Liderança: A Fórmula Multiplex [Leadership: The Multiplex Formula]. Lisbon: Edições Sílabo. 
Parreira, A. \& Lorga da Silva, A. (2016). The use of numerical value of adverbs of quantity and frequency in the measurement of behavior patterns: transforming ordinal scales into interval scales. Revista Ensaio - Avaliação $e$ Políticas Públicas em Educação, 24(90), 109-126. https://doi.org/10.1590/S0104-40362016000100005

Pestana, H., Parreira, A., \& Moutinho, L. (2020). Motivations, emotions and satisfaction: The keys to a tourism destination choice. Journal of Destination Marketing \& Management, 16, 100332. https://doi.org/10.1016/j.jdmm. 2018.12.006

Prigogine, I., \& Stengers, I. (1997). A nova aliança: metamorfose da ciência. [The new Alliance: Science Metamorphosis]. Brasília: Editora UnB

Prigogine, I., \& Stengers, I. (2009). Entre le Temps et l'Éternité. [Between Time and Eternity]. Paris: Flammarion

Prigogine, I. (1997). The End of Certainty: Time, Chaos, and the New Laws of Nature. New York: The Free Press.

Schneider, M., \& Somers, M. (2006). Organizations as complex adaptive systems: Implications of Complexity Theory for leadership research. The Leadership Quarterly, 17(4), 351-365. https://doi.org/10.1016/j.leaqua.2006.04.006

Sher, G. (1999). What is Tarski's Theory of Truth?. Topoi 18, 149-166. https://doi.org/10.1023/A:1006246322119

Schröder, H. M. (1971a). Conceptual Complexity and Personality Organization. In: Schröder and Suedfeld (Eds.) Personality Theory and Information Processing. Ronald Press.

Simon H. A. (1962). The Architecture of Complexity. Proceedings of the American Philosophical Society, 106(6), 467-482. http://www.jstor.org/stable/985254

(1987). Bounded rationality. In J. Eatwell, M. Milgate, and P. Newman (Eds.). The New Palgrave Dictionary of Economics (Vol. 1, pp. 266-268). London, England: Macmillan.

Skow, B. (2015). Objective Becoming. Oxford: Oxford Scholarship

Streufert, S., \& Streufert, S. C. (1969). Effects of conceptual structure, failure, and success on attribution of causality and interpersonal attitudes. Journal of Personality and Social Psychology, 11(2), 138-147. https://doi.org/10.1037/h0027047

Streufert, S., \& Streufert, S. C. (1978). Behavior in the complex environment. V. H. Winston \& Sons.

Streufert, S., \& Swezey, R. W. (1986). Complexity, managers, and organizations. Academic Press.

Streufert, S. (2006). Complexity: An Integration of Theories. Journal of Applied Social Psychology 27(23), 2068-2095. https://doi.org/10.1111/j.1559-1816.1997.tb01641.x

Uhl-Bien, M., Marion, R., \& McKelvey, B. (2007). Complexity Leadership Theory: Shifting leadership from the industrial age to the knowledge era. The Leadership Quarterly, 18(4), 298-318. https://doi.org/10.1016/j.1 eaqua.2007.04.002

UN (2017). UN 20/30 agenda: Ministerial Declaration on Sustainable Development. July 19, 2017 Session, 46th Meeting.

Wiener, N. (1961). Cybernetics, or control and communication in the animal and the machine (2nd ed.). MIT Press; John Wiley \& Sons Inc. https://doi.org/10.1037/13140-000

\section{PARADIGMA KOMPLEKSNOSTI: JEDAN MODEL ANALIZE SOCIJALNIH SISTEMA I PROBLEMA}

Ovaj rad predlaže paradigmu kompleksnosti kao inovativno rasuđivanje za analizu problema $u$ bihevijoralnim naukama. Počinje objašnjavanjem doprinosa najvažnijih autora koji su se bavili kompleksnom paradigmom rasuđivanja: Gedela, Prigožina i Morina. Oni nude osnovu za model analize i procene kompleksnih sistema i problema (ACSIP Model). Objašnjena su četiri postulata Modela i naglašena glavna hipoteza Modela - nivo kognitivnih operacija je najvažniji faktor kompleksnosti Sistema; da bi ga razumeli, kognitivni nivo analize mora da bude najmanje jednak nivou Sistema ili problema koji se analizira. $U$ drugom delu rada, ilustrativna primena ACSIP Modela se primenjuje na analizu SDG 9 iz UN agende 20/30, pokazujući analizu kompleksnog problema koju vodi model kompleksnog rasuđivanja. Nakon toga, predstavljeno je empirijsko istraživanje da bi se verifikovala hipoteza četvrtog postulata modela. Rezultati potvrđuju hipotezu: korišćenje informacija od strane grupe je obrnuto proporcionalno korišćenju autoriteta (moći). Ovi rezultati nas navode da zaključimo da je paradigma kompleksnog rasuđivanja obećavajuće alatka za dobijanje sinergijskih rezultata u naučnoj analizi i rešavanju konkretnih socijalnih problema $i$ da se suočimo sa kompleksnim izazovima koje donose sistemi veštaačke inteligencije.

Ključne reči: Morinovi operateri; kognitivna kompleksnost; ACSIP Model; Socioekonomske nejednakosti, Sinergija rezultata 